ScIDice

\section{Knowledge Awareness and Practice on Assessment of Marginal Fit in Fixed Partial Dentures among Undergraduates}

\section{International Journal of Dentistry and Oral Science (IJDOS) ISSN: $2377-8075$}

Pooja Umaiyal. $\mathrm{M}^{1}$, V. Ashok ${ }^{2 *}$, Jaiganesh Ramamurthy ${ }^{3}$

${ }^{1}$ Saveetha Dental College and Hospitals, Saveetha Institute of Medical and Technical Sciences, Saveetha University, Chennai, India.

${ }^{2}$ Professor and Head, Department of Prosthodontics, Saveetha Dental College and Hospitals, Saveetha Institute of Medical and Technical Sciences, Saveetha University, Chennai, 600077, India.

${ }^{3}$ Professor and Head, Department of Prosthodontics, Saveetha Dental College and Hospitals, Saveetha Institute of Medical and Technical Sciences, Saveetha University, Chennai, 600077, India.

\title{
Abstract
}

The importance of Marginal adaptation of fixed prosthodontics is to assess the smallest number of gap measurement on margins of single Crowns to get relevant results for gap analysis. Factors affecting marginal adaptation of fixed prosthodontics include the type of finish line, the material used for impression, the luting cement and other factors include the method of fabrication. The aim is to assess the knowledge and attitude towards the marginal fit in fixed partial denture among the undergraduate and its application in their day-to-day practice. A cross sectional study was conducted online with a pre-structured questionnaire containing 10 questions among the 100 undergraduates. Persistent data was extracted and analysed. Nearly $93.9 \%$ of the surveyed population chose putty with a light body as the choice of impression material. $99 \%$ of the population agreed the necessity of gingival retraction which dictates the outcome of the treatment. Majority chose Resin modified glass ionomer cement (RMGIC) as the best luting cement that accounted for the majority for retention. The knowledge, awareness level, and their application in clinical practice showed significant variation. Within the limits of this study, the highest predominance of impression material to record the best of the preparation is by the use of putty with light body, $99 \%$ of the students opted for gingival cord playing a major role in marginal fit of fixed partial dentures. These were assessed along with other factors that might affect the accuracy of marginal fit and also the consequence of an improper fit was assessed.

Keywords: Fixed Partial Denture; Gingival Retraction Cord; Prosthesis; Resin Modified GIC.

\section{Introduction}

The vicious cycle that leads to the derangement of the dentition starts by the tooth loss and failure to replace missing teeth.Replacement of the edentulous space plays a major role in maintaining the esthetics and the harmonious functioning of the stomatognathic system. Loss of tooth causes disabilities in daily living activities as phonetics, impaired eating or social embarrassment [1]. Thus this requires restoration by a prosthesis. There are various treatment modalities to replace missing teeth. Most patients go for fixed prosthesis rather than removable for the ease of routine.
A fixed prosthesis can be used to restore single or multiple teeth and it takes support of the adjacent teeth called as abutments. The aim of the fixed partial denture is to restore function and esthetic without hampering the oral and general health of the patients [2]. For a good prognosis of fixed partial denture, various steps in fabrication need to be critically appraised, inoculated and practiced. General structures taken in account for fixed partial dentures to examine the type of defect at the edentulous site, the root surface area, the condition of the abutment teeth, crownroot ratio, cross-section, span of edentulism, gingival recession, stability of the abutment teeth and bone loss.

The survival of fixed partial dentures depends on the state of marginal adaptation. Marginal gaps can create a favorable condi-

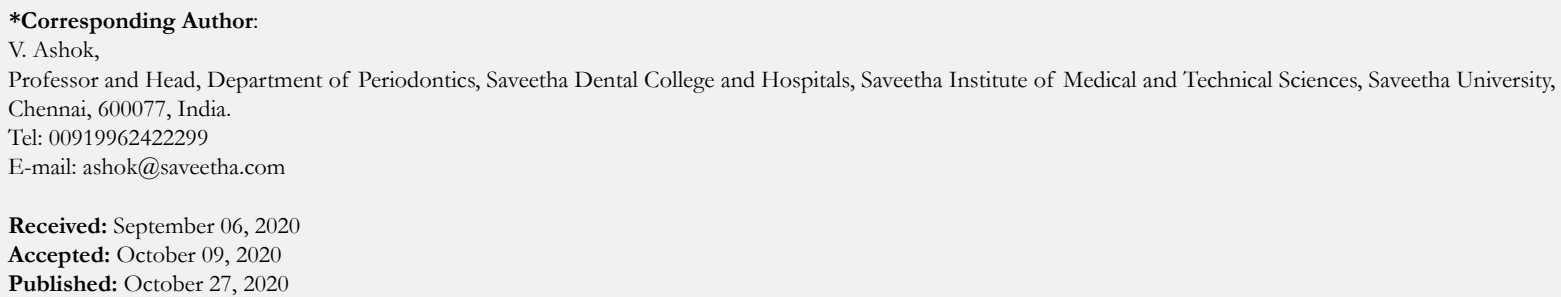

Copyright: V. Ashok ${ }^{\circ} 2020$. This is an open-access article distributed under the terms of the Creative Commons Attribution License, which permits unrestricted use, distribution and reproduction in any medium, provided the original author and source are credited. 
tion for biofilm deposition, thereby contributing to the development of caries and periodontal disease [3]. Ill fitting restoration potentially affects the abutment teeth and supporting periodontium as it provides access and host for oral bacterial adherence which can cause secondary caries and traumatic periodontal irritation [4]. Luting cement fills space between a fixed prosthesis and the prepared tooth as precise well fitting cast metal restorations have some discrepancies between the margins of the restoration and the preparation of abutment tooth [5].

A problem recognised during the cementation process of the crown is that the cementing medium may prevent the seating of the crown, causing inadequately sealed margins and positioning it in hyper occlusion. After final cementation, open margins cause the abutment teeth to become sensitive for prolonged periods. Premature crown loosening occurs due to inadequately sealed margins along with occlusal discrepancies [6].

The escape of cement at the margins decreases as the crown is seated on a prepared tooth. Different escapes of cement during the cementation process is seen on different finish lines. Hence the accuracy of well adapted margins of fixed partial denture is considered the primary factor in determining the long term success of any prosthesis [7].

Previously our team had conducted numerous clinical trials, invitro studies8, comparative studies [9-11], case reports [12], SEM analysis [13], systemic reviews [14-16], surveys [17, 18] and reviews [19-22] over the past many years. Now we are focusing on epidemiological studies. The idea for this study stemmed from the current interest in our community. The aim of this study was to provide and assess knowledge of marginal fit of fixed partial dentures among the dental undergraduates.

\section{Materials and Methods}

The study was conducted among the dental undergraduates. The advantage of this study being conducted online was the ease of data collection containing similar ethnicity with the involvement of both the genders. The unavailability of location specific data was the disadvantage of this study. Ethical clearance was obtained from the institutional ethical committee.

A questionnaire containing 10 questions was prepared to assess the knowledge on the marginal fit of fixed partial dentures. This was circulated among the dental undergraduates through mail and whatsapp as an online survey. A total of 100 undergraduate students attended the survey. Sampling bias for the study was minimised by stratification and randomization. Internal validity included a pre tested questionnaire and the external validity was the diversity of it to be applicable to dental graduates.

Data collection was done by the use of online questionnaire forms that had 10 questions regarding the field of integral requirements to achieve proper marginal fit. Google form was used for data collection from the surveyors. This collected data included age, gender, year of study and the questions. This data was then tabulated in excel and then imported to SPSS software.

Statistical test was run using chi-square test with statistical analysis software SPSS by IBM. Its dependent variables include the marginal fit of fixed partial dentures whereas its independent variables include age and gender of the participants. All of these were analysed using correlation and association.

\section{Results and Discussion}

A total of 100 undergraduates attended the online survey among which $78.8 \%$ were interns followed by $12.12 \%$ and $9.1 \%$ of third years and final year dental undergraduates respectively (Figure 1). Most predominantly $57.58 \%$ of the participants prepared less than five FPDs in a year (Figure2). When questioned on the sufficiency of impression material for accurate impression $93.9 \%$ chose putty with light body (Figure 3). $99 \%$ of the subjects agreed to the statement of the gingival retraction cord dictates the outcome of the treatment. The prevalence of metal/coping fit trail was predominantly done for all the cases by $69.7 \%$ of the participants (Figure 4). 15.15\%,12.1\% and 3\% of the subjects reported the consequences of improper marginal fit to be secondary caries, gingival recession and crown dislodgement respectively, whereas the majority of the population $(69.7 \%)$ chose all the above mentioned characteristics as the effect of improper marginal fit (Figure 5). All the above options that included internal relief, modified cementation techniques and venting was predominantly opted by $63.64 \%$ (Figure 6). Based on the year of study, the most appropriate finish line for the best marginal fit was opted to be shoulder finish line $36.4 \%$, followed by shoulder with bevel finish line with $33.6 \%$ and it is statistically significant with $\mathrm{p}$ value $<0.05$ (Figure 7). Regarding to the cement used for the luting $57.6 \%$ of the population chose Resin modified glass ionomer cement as the cement of choice as it provides better adaptation of the crown to the abutment followed by GIC with $36.4 \%$ and it is also statistically

Figure 1. Bar chart representing the distribution of survey participants based on the year of study. X axis represents the year of study and $\mathrm{Y}$ axis represents the number of participants in terms of percentage. Predominantly noticed group of participants were interns followed by third years and then final years.

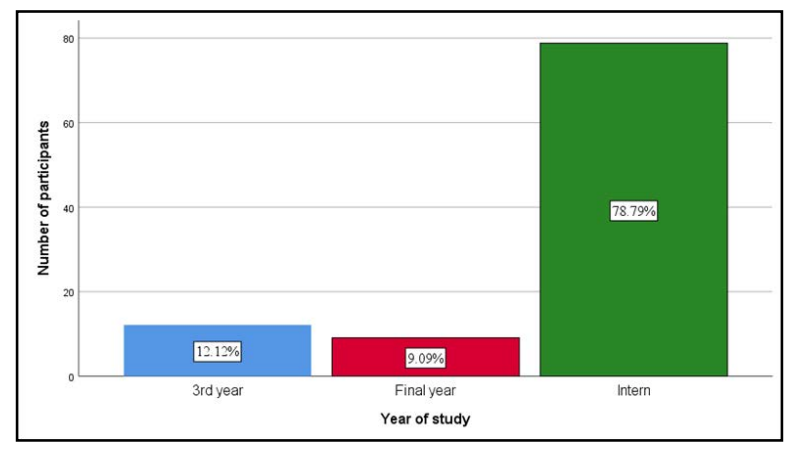


Figure 2. Bar chart representing the distribution of responses based on the number of fixed partial dentures performed in a year. $\mathrm{X}$ axis denotes the number of fixed partial dentures performed in a year and $\mathrm{Y}$ axis denotes the number of participants in terms of percentage. Most predominantly $\mathbf{5 7 . 5 8 \%}$ of the participants prepared less than five FPDs in a year.

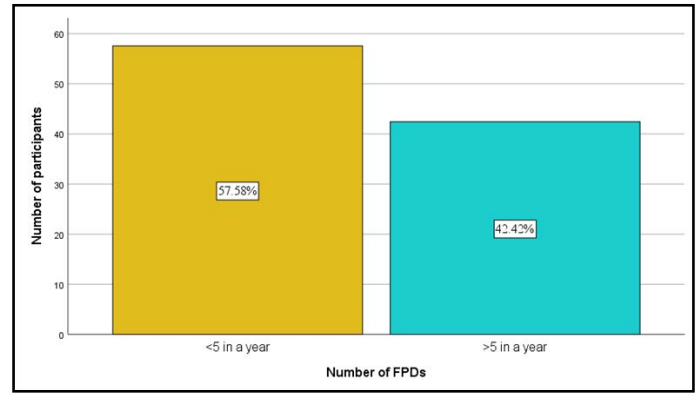

Figure 3. Bar chart representing the distribution of responses based on the sufficiency of impression material. $\mathrm{X}$ axis denotes the type of impression material and $\mathrm{Y}$ axis denotes the number of participants in terms of percentage. The most predominantly opted impression material for accuracy was putty with light body followed by alginate.

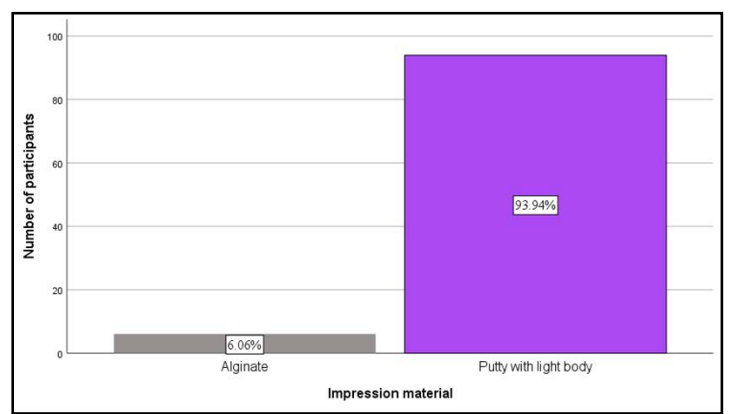

Figure 4. Bar chart representing the distribution of responses based on the frequency of metal fit/coping fit trial. $\mathrm{X}$ axis denotes the number of cases undergoing metal/ coping fit trial and $\mathrm{Y}$ axis denotes the number of participants in terms of percentage. The prevalence of metal/coping fit trail was predominantly done for all the cases by the participants.

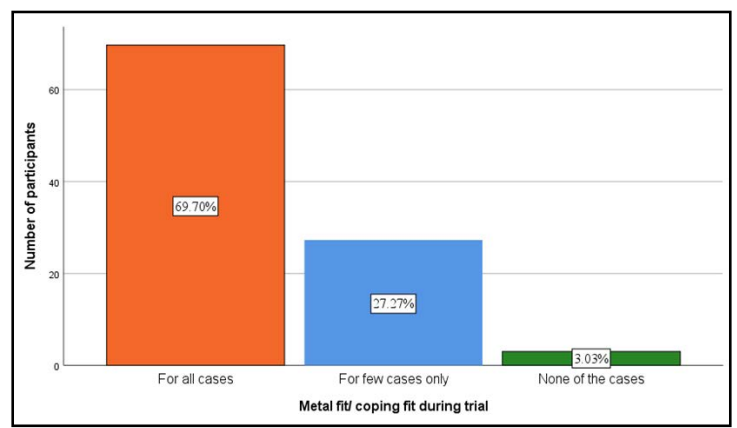

Figure 5. Bar chart representing frequency distribution of the consequences of improper marginal fit. $X$ axis denotes the consequences of improper marginal fit and $\mathrm{Y}$ axis denotes the number of participants in terms of percentage. The predominantly opted consequence of improper marginal fit by the undergraduates included all the above options with $69.7 \%$.

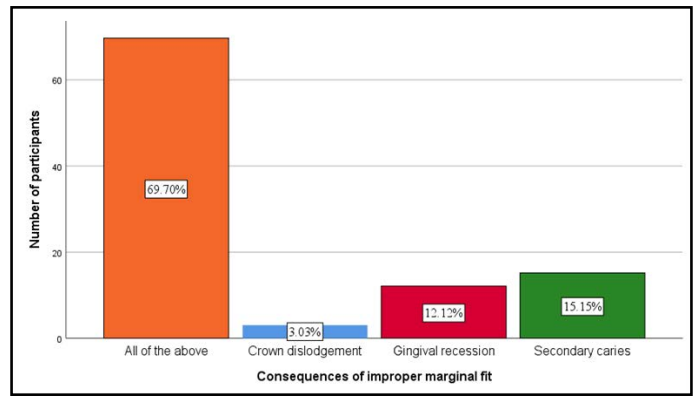

significant with $\mathrm{p}$ value $<0.05$ (Figure 8 ).

Replacement of missing teeth has been one of the most sought after dental treatments over the decades. Dental caries and periodontal diseases play a major role in the loss of tooth, the incidence of complete edentulousness is common in the latter half of the sixth decade and seventh decade of life. With an increase in dental awareness, people of all economic groups report to replacement of missing teeth. With a majority opting fixed partial denture as a treatment of choice due to economic reasons or insufficient bone density for implants. 
Figure 6. Bar chart representing frequency distribution of the responses based on the techniques to improve improper marginal fit. $\mathrm{X}$ axis denotes the techniques to improve improper marginal fit and $\mathrm{Y}$ axis denotes the number of participants in terms of percentage. The predominantly opted technique to improve improper marginal fit by the undergraduates included all the above options that included internal relief, modified cementation techniques and venting.

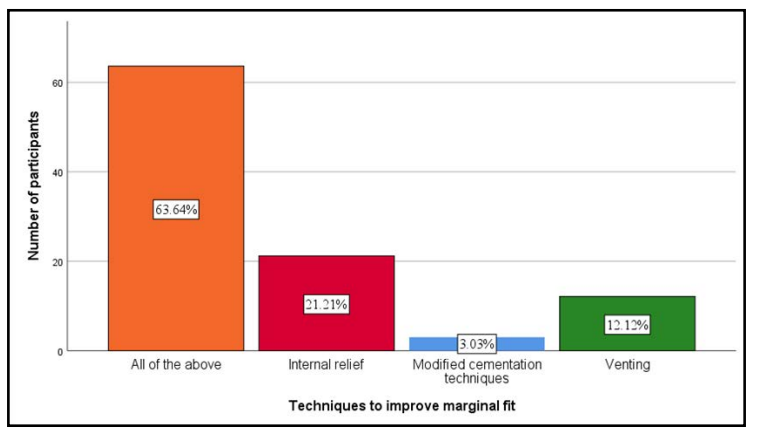

Figure 7. Bar chart represents the comparison of responses based on the type of finish lines. X-axis represents the year of study of the participants and $\mathrm{Y}$ axis represents the number of participants in terms of percentage. According to the type of finish line for best marginal fit, the prevalence of shoulder finish line was more predominant than shoulder with bevel. However the association was found to be statistically significant with $\mathrm{p}$ value $<0.05$. (Pearson Chi Square: 17.365 , df: 6 , p value: $0.008(<0.05))$.

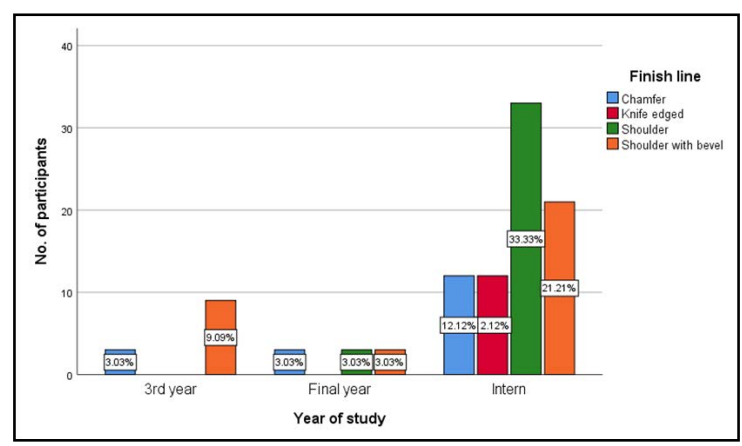

Figure 8. represents the best luting cement according to the undergraduates. $\mathrm{X}$ axis represents the year of study of the participants and $\mathrm{Y}$ axis represents the number of participants in terms of percentage. The prevalence of RMGIC (57.6\%) as a luting cement for better adaptation of crown was more predominant than other types of cements. However the association was found to be statistically significant with a $\mathrm{p}$ value $<0.05$. (Pearson Chi Square: 11.534 , df: 4 , p value: $0.021(<0.05)$ ).

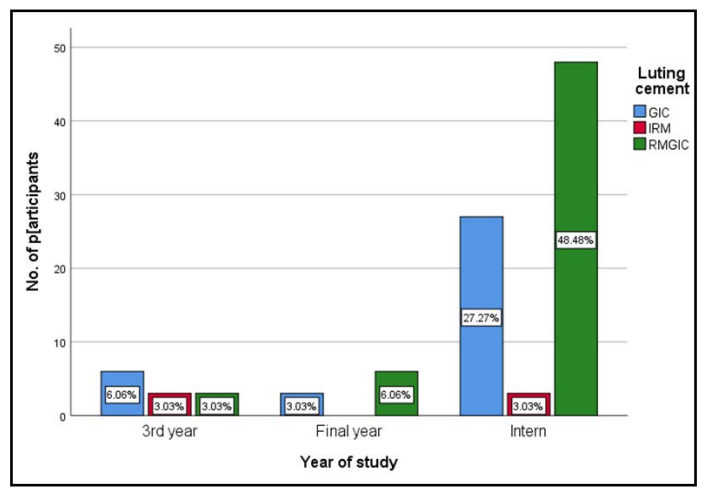

This study was aimed to assess the skills and knowledge of the students towards the marginal fit of fixed partial dentures. Holmes et al. [23], defined an external marginal gap and an internal marginal gap that was also influenced by the horizontal over extension and under extensions of the restoration margin. Various methods are present to measure the marginal adaptation of crowns due to complex gap morphology and also the number of sites measured. Certain factors that affect marginal adaptation include margin design, tooth preparation, casting procedures, alloy types, porcelain, firing cycles and cementation techniques.

Gingival retraction being a mandatory procedure of isolation aiding in the precise recording of the prepared and unprepared surface of abutment teeth [24]. However. 99\% of the surveyed population stated that they felt gingival retraction cord dictates the outcome of the treatment. This was contradicted by a study by Abinaya kannan et al. [25], in which the majority of the sur- veyed population felt that gingival retraction cord did not dictate the outcome of the treatment and $61 \%$ of the crowd did not perform cord packing in their practice.

Impression making is an important step towards producing the fixed prosthesis. It is to replicate or to reproduce the tooth that is prepared. It provides information about the prepared teeth, surrounding teeth and associated soft tissues by creating a negative replica of these structures. Soft tissue can be damaged when the impression material extends subgingivally 16. Material of choice for recording the preparation, which has the standard in terms of dimensional stability, precision in recording and replicating is putty with light body $[26,27]$. The predominant choice of the surveyed subjects was the use of putty with light body followed by alginate. Similar findings were found in a study by Abinaya Kannan et al. [25], with putty and light body being the impression material of choice for $85 \%$ of the practitioners. 
In the present study, shoulder was the best finish line opted by the majority of the surveys. This was accordingly supported by Jei et al. [28], stating that shoulder and shoulder-bevel designs were found to have less marginal distortion than chamfer designs. Hilggert et al., and Nemane et al. [29], showed the best finish line as a round shoulder for the proper marginal fit. These were contraindicated by Probster et al.[3], whose study showed a higher prevalence of deep chamfer.

A wide array of luting cement is available for cementation of fixed prosthesis. A critical evaluation of mechanical, chemical and biological properties of the material is vital for choice of luting cement. In this survey, the best luting cement was found to be RMGIC. This was contraindicated by Abinaya Kannan et al. [25], which reported GIC being the highest prevalence.

The limitation of this study conducted includes the reduction or availability of the number of participants, the unequal distribution of questionnaires. Hence, the results of this study must be interpreted with the limitations of this survey and further study must be done including larger participants. Such surveys should also include certain associated parameters like the shade of choice, method fabrication, reliefs, etc.

\section{Conclusion}

Within the limits of this study, the highest predominance of impression material used to record the best of the preparation is by the use of putty with light body, 99\% of the students opted for the gingival cord playing a major role in the marginal fit of fixed partial dentures. These were assessed along with other factors like the use of luting cement and finish line that might affect the accuracy of marginal fit and also the consequence of an improper fit was assessed.

\section{Authors' Contributions}

Conceptualisation: Pooja Umaiyal and Ashok V; methodology: Pooja Umaiyal and Ashok V; validation: Pooja Umaiyal and Ashok V; formal analysis: Pooja Umaiyal and Ashok V; writingoriginal draft preparation: Pooja Umaiyal; writing-review and editing:Ashok V;visualisation: Jaiganesh.

\section{References}

[1]. Shigli K, Kakodkar P, Agrawal N, Hebbal M, Huddar D, Vikneshan M. Perception and knowledge of dental interns toward interdepartmental coordination for successful prosthodontic treatment: A pilot study. J Indian Prosthodont Soc. 2015 Oct-Dec;15(4):342-8.Pubmed PMID: 26929538.

[2]. Bader JD, Rozier RG, McFall WT Jr, Ramsey DL. Effect of crown margins on periodontal conditions in regularly attending patients. J Prosthet Dent. 1991 Jan;65(1):75-9.Pubmed PMID: 2033551.

[3]. Groten M, Axmann D, Pröbster L, Weber H. Determination of the minimum number of marginal gap measurements required for practical in-vitro testing. J Prosthet Dent. 2000 Jan;83(1):40-9.Pubmed PMID: 10633021.

[4]. Knoernschild KL, Campbell SD. Periodontal tissue responses after insertion of artificial crowns and fixed partial dentures. J Prosthet Dent. 2000 Nov;84(5):492-8.Pubmed PMID: 11105004.

[5]. Sharma S, Patel JR, Sethuraman R, Singh S, Wazir ND, Singh H. A Comparative Evaluation of the Effect of Resin based Sealers on Retention of Crown Cemented with Three Types of Cement - An In Vitro Study. J Clin Diagn Res. 2014 Mar;8(3):251-5.Pubmed PMID: 24783150.

[6]. Gavelis JR, Morency JD, Riley ED, Sozio RB. The effect of various finish line preparations on the marginal seal and occlusal seat of full crown preparations. J Prosthet Dent. 2004 Jul 1;92(1):1-7.

[7]. Byrne G. Soldering in prosthodontics--an overview, part I. J Prosthodont. 2011 Apr;20(3):233-43.Pubmed PMID: 21323788

[8]. Ajay R, Suma K, Ali SA, Kumar Sivakumar JS, Rakshagan V, Devaki V, et al. Effect of Surface Modifications on the Retention of Cement-retained Implant Crowns under Fatigue Loads: An In vitro Study. J Pharm Bioallied Sci. 2017 Nov;9(Suppl 1):S154-S160.Pubmed PMID: 29284956.

[9]. Duraisamy R, Krishnan CS, Ramasubramanian H, Sampathkumar J, Mariappan S, Navarasampatti Sivaprakasam A. Compatibility of Nonoriginal Abutments With Implants: Evaluation of Microgap at the Implant-Abutment Interface, With Original and Nonoriginal Abutments. Implant Dent. 2019 Jun;28(3):289-295.Pubmed PMID: 31124826.

[10]. Jyothi S, Robin PK, Ganapathy D. Periodontal health status of three different groups wearing temporary partial denture. Res J Pharm Technol. 2017;10(12):4339-42.

[11]. Ganapathy D, Sathyamoorthy A, Ranganathan H, Murthykumar K. Effect of Resin Bonded Luting Agents Influencing Marginal Discrepancy in All Ceramic Complete Veneer Crowns. J Clin Diagn Res. 2016 Dec;10(12):ZC67ZC70.Pubmed PMID: 28209008.

[12]. Ashok V, Nallaswamy D, Benazir Begum S, Nesappan T. Lip Bumper Prosthesis for an Acromegaly Patient: A Clinical Report. J Indian Prosthodont Soc. 2014 Dec;14(Suppl 1):279-82.Pubmed PMID: 26199531.

[13]. Ranganathan H, Ganapathy DM, Jain AR. Cervical and Incisal Marginal Discrepancy in Ceramic Laminate Veneering Materials: A SEM Analysis. Contemp Clin Dent. 2017 Apr-Jun;8(2):272-278.Pubmed PMID: 28839415.

[14]. Kannan A. Effect of Coated Surfaces influencing Screw Loosening in Implants: A Systematic Review and Meta-analysis. World. 2017 Nov;8(6):496502.

[15]. Jain AR, Nallaswamy D, Ariga P, Ganapathy DM. Determination of correlation of width of maxillary anterior teeth using extraoral and intraoral factors in Indian population: A systematic review. World J Dent. 2018 Jan;9:68-75.

[16]. Kannan A, Venugopalan S. A systematic review on the effect of use of impregnated retraction cords on gingiva. Res J Pharm Technol. 2018;11(5):2121-6.

[17]. Ashok V, Suvitha S. Awareness of all ceramic restoration in rural population. Res J Pharm Technol. 2016;9(10):1691-3.

[18]. Basha FYS, Ganapathy D, Venugopalan S. Oral Hygiene Status among Pregnant Women Res J Pharm Technol. 2018;11:3099.

[19]. Jain AR, Nallaswamy D, Ariga P, Ganapathy DM. Determination of correlation of width of maxillary anterior teeth using extraoral and intraoral factors in Indian population: A systematic review. World J Dent. 2018 Jan;9:68-75.

[20]. Selvan SR, Ganapathy D. Efficacy of fifth generation cephalosporins against methicillin-resistant Staphylococcus aureus-A review. Res J Pharm Technol. 2016;9(10):1815-8.

[21]. Subasree S, Murthykumar K. Effect of Aloe Vera in Oral Health-A Review. Res J Pharm Technol. 2016;9(5):609-12.

[22]. Venugopalan S, Ariga P, Aggarwal P, Viswanath A. Case Report: Magnetically retained silicone facial prosthesis. Niger J Clin Pract. 2014 Mar 27:17(2):260-4.

[23]. Holmes JR, Bayne SC, Holland GA, Sulik WD. Considerations in measurement of marginal fit. J Prosthet Dent. 1989 Oct 1;62(4):405-8.

[24]. Rosella D, Rosella G, Brauner E, Papi P, Piccoli L, Pompa G. A tooth preparation technique in fixed prosthodontics for students and neophyte dentists. Ann Stomatol (Roma). 2016 Feb 12;6(3-4):104-9.Pubmed PMID: 26941898.

[25]. Kannan A, Venugopalan S, Ganapathy DM, Jain AR. A knowledge, attitude, and practice survey on the methodology followed in the fabrication of fixed partial denture amongst private practitioners. Drug Invention Today. 2018 Aug 1;10(8):1349-56.

[26]. S S, Ma VS, Mi VS, F HG, M H. Gingival Retraction Methods for Fabrication of Fixed Partial Denture: Literature Review. J Dent Biomater. 2016 Jun;3(2):205-213.Pubmed PMID: 28959744.

[27]. Gupta A, Prithviraj DR, Gupta D, Shruti DP. Clinical evaluation of three new gingival retraction systems: a research report. J Indian Prosthodont Soc. 2013 Mar; 13(1):36-42.Pubmed PMID: 24431705.

[28]. Jei JB, Mohan J. Comparative Evaluation of Marginal Accuracy of a Cast Fixed Partial Denture Compared to Soldered Fixed Partial Denture Made of Two Different Base Metal Alloys and Casting Techniques: An In vitro Study. J Indian Prosthodont Soc. 2014 Mar; 14(1):104-9.Pubmed PMID: 24605006.

[29]. Nemane V, Akulwar RS, Meshram S. The Effect of Various Finish Line Configurations on the Marginal Seal and Occlusal Discrepancy of Cast Full Crowns After Cementation - An In-vitro Study. J Clin Diagn Res. 2015 Aug;9(8):ZC18-21.Pubmed PMID: 26436039. 